\title{
Comparison of endoscopic and pathological findings of the upper gastrointestinal tract in transplant candidate patients undergoing hemodialysis or peritoneal dialysis treatment: a review of literature
}

Mehmet Usta', Alparslan Ersoy², Yavuz Ayar ${ }^{1 *}$ (D), Gökhan Ocakoğlư ${ }^{3}$, Bilgehan Yuzbasioglư ${ }^{4}$ Emrullah Düzgün Erdem ${ }^{4}$ and Omer Erdogan ${ }^{5}$

\begin{abstract}
Background: Dyspepsia is a common disorder in kidney transplant recipients, and the risk of post-transplant complications is increased in candidates with upper gastrointestinal disease. We evaluated gastrointestinal lesions of kidney transplant candidates on dialysis.

Methods: In this study, endoscopic and pathological findings in hemodialysis (HD) and peritoneal dialysis (PD) patients with gastrointestinal symptoms on the waiting list were compared.

Results: The most common non-ulcerous lesions in the endoscopic examination were gastritis (62.3\%), erosive gastritis (38.7\%), duodenal erosion or duodenitis (18.9\%) and esophagitis (13.2\%). The ulcerous lesion was present in only 3 patients. Gastroesophageal reflux disease, ulcerated lesion and non-ulcerated lesion rates were similar in both dialysis groups. Histopathological examination revealed Helicobacter pylori (HP) positivity in $28.3 \%$ of patients. HP positivity rate was significantly higher in PD patients than in HD patients (38.7\% vs. 13.6\%, $p=0.046)$. Chronic gastritis (75.5\%) was the most common pathological finding. HP positivity rate was $37.5 \%$ in patients with chronic gastritis, but HP was negative in patients without chronic gastritis. In multivariate analysis, male gender, urea and albumin levels were associated with the presence of pathological chronic gastritis. The presence of gastritis, total cholesterol and ferritin levels were found significant for HP positivity. A total cholesterol $>243 \mathrm{mg} / \mathrm{dL}$ was significantly related to an increased risk of the presence of HP positivity.

Conclusions: Gastrointestinal lesions and HP infection are common in dialysis patients. Dialysis modality may affect the frequency of some lesions. It may be useful to have an endoscopic examination before entering the transplant waiting list for all candidates.
\end{abstract}

Keywords: Hemodialysis, Peritoneal dialysis, Transplant waiting list, Endoscopy, Gastritis, Helicobacter pylori

\footnotetext{
* Correspondence: yavuzayar@hotmail.com

'Bursa City Hospital, Department of Nephrology, Nephrology Clinic, Dogankoy mevki, Nilufer, Bursa, Turkey

Full list of author information is available at the end of the article
}

C C The Author(s). 2020 Open Access This article is licensed under a Creative Commons Attribution 4.0 International License, which permits use, sharing, adaptation, distribution and reproduction in any medium or format, as long as you give appropriate credit to the original author(s) and the source, provide a link to the Creative Commons licence, and indicate if changes were made. The images or other third party material in this article are included in the article's Creative Commons licence, unless indicated otherwise in a credit line to the material. If material is not included in the article's Creative Commons licence and your intended use is not permitted by statutory regulation or exceeds the permitted use, you will need to obtain permission directly from the copyright holder. To view a copy of this licence, visit http://creativecommons.org/licenses/by/4.0/. The Creative Commons Public Domain Dedication waiver (http://creativecommons.org/publicdomain/zero/1.0/) applies to the data made available in this article, unless otherwise stated in a credit line to the data. 


\section{Background}

Dyspeptic complaints such as vomiting, anorexia, abdominal pain, souring and belching are common in patients with chronic kidney disease [1, 2]. Uremic patients have a high risk of gastroduodenal discomfort due to high urea levels, increased gastrin level, gastric acid hypo- and hypersecretion, decreased gastrointestinal motility, amyloid deposition, and Helicobacter pylori (HP) infection [2-4]. However, the deterioration in psychological general wellbeing may be associated with a high prevalence of gastrointestinal symptoms in patients with chronic kidney disease (CKD), regardless of presence of dialysis or diabetes mellitus or not, and type of dialysis [1].

HP infection, which is common all over the world and in our country $[5,6]$, can cause gastritis, peptic (gastric or duodenal) ulcer, gastric cancer and gastric lymphoma (primary gastric B cell lymphoma, MALT lymphoma) [7, 8]. Although some studies report the prevalence of HP infection in dialysis patients to be lower than the normal population [9, 10], it ranges from 15 to $74.4 \%$ in normal population and 20 to $64 \%$ in CKD patients [11-13]. Recently, many studies have also shown that HP infection plays an important role in the development of gastrointestinal complications such as heartburn, peptic ulcer disease, gastric erosion in hemodialysis (HD) or continuous ambulatory peritoneal dialysis (PD) patients $[9,14,15]$. The risk of malignancy in dialysis patients is also increased. Endoscopic examination of dyspeptic symptoms is the most appropriate diagnostic approach. Candidate patients on the kidney transplant waiting list are carefully evaluated for absolute and relative contraindications before transplantation. The transplant recipients are susceptible to a variety of gastrointestinal complications such as infections, ulcer disease and malignancies [16]. In addition, immunosuppressive drugs, especially corticosteroids, used after kidney transplantation have adverse effects on the gastrointestinal tract (peptic ulcer bleeding, perforation, gastritis and esophagitis). Therefore, it is recommended that transplant candidates with gastrointestinal complaints or suspected malignancy should be undergo endoscopy prior to transplantation and treated if necessary. This study aimed to evaluate the results of upper gastrointestinal endoscopy in dialysis patients who are candidates for kidney transplantation.

\section{Methods}

We evaluated adult 129 dialysis patients (45 PD, 84 HD) over 18 years of age who were candidates for kidney transplantation. Among all patients, 53 patients (34 males, 19 females) who underwent upper gastrointestinal endoscopy for gastrointestinal symptoms were included in the study. Ethical approval was obtained, and all participants provided written informed consent. Patients were divided into two groups: PD ( $n=31,20$ males, 11 females $)$ and HD $(n=22$, 14 males, 8 females) groups. Anti-HCV and anti-
HIV were negative in all patients. In the HD group, 1 patient had hepatitis B positivity. The clinical characteristics, esophagogastroduodenoscopy findings and biopsy (histological evaluation and identification of HP-staining) results were obtained from the medical records, retrospectively.

\section{Statistical analysis}

A Shapiro-Wilk test was used to assess whether the variables followed normal distribution. Categorical variables were given as number and percentage, and continuous variables as mean \pm standard deviation $(\mathrm{SD})$ or median (min:max). According to the normality test results, Mann Whitney $U$ test or independent samples t-tests were used to compare the groups. Categorical variables were compared by Chi square test and Fisher's exact test. To determine the independent risk factors affecting the presence of endoscopic gastritis and duedonitis and pathological chronic gastritis and HP, binary logistic regression analysis was performed. The covariates that had a $P$ value $<0.2$ in the univariate analysis were included in the multivariable logistic regression analysis, and forward selection and backward elimination method was used in finding the best parsimonious final model. In order to estimate the sensitivity and specificity of hemoglobin, urea and total cholesterol for predicting the presence of duodenitis, chronic gastritis and HP positivity receiver operator characteristic (ROC) curve analysis was performed. The data was analyzed using the SPSS Software (IBM Corp. Released 2015. IBM SPSS Statistics for Windows, Version 23.0. Armonk, NY: IBM Corp). A $p$ value of $<0.05$ was considered statistically significant.

\section{Conflict of interest}

There is no conflict of interest in our study. The study was retrospective and no funding was received.

\section{Results}

The mean age in the HD group was higher than in the PD group $[65.4 \pm 11.5(30-79)$ vs. $56.2 \pm 13.2(29-86)$ years, $p=0.005]$. The mean dialysis durations were similar in the HD [46.0 $\pm 39.6(6.96-171.2)$ months] and PD [42.0 $\pm 45.9(1.25-138.6)$ months] groups $(p=0.295)$. Diabetes melllitus ratio ( $38.7 \%$ vs. $27.3 \%)$, gender and primary disease distributions were not different in the PD and HD groups, respectively. The hypertension ratio in PD group was higher than HD group (67.7\% vs. $4.5 \%$, $p<0.001)$. When compared with $\mathrm{PD}$ group, $\mathrm{Kt} / \mathrm{V}$ value $(1.76 \pm 0.35$ vs. $2.21 \pm 0.35, \mathrm{p}<0.001)$, serum calcium levels $(9.10 \pm 0.63$ vs. $9.66 \pm 0.87 \mathrm{mg} / \mathrm{dL}, p=0.017)$ and total iron binding capacity was lower $(95.7 \pm 53.7$ vs. $201.7 \pm 47.7 \mathrm{mcg} / \mathrm{dL}, \mathrm{p}<0.001)$, and transferrin saturation (TSAT: $237 \pm 317$ vs. $39.8 \pm 15.6 \%, p=0.001$ ) and ferritin (758 \pm 701 vs. $235 \pm 191 \mathrm{mcg} / \mathrm{L}, p=0.011)$ levels were higher in HD group, respectively. There was no 
significant difference between serum creatinine, uric acid, glucose, HbA1c, lipid profile, electrolytes, total protein, albumin, liver function tests, lypase, iron, phosphorus, calcium $\mathrm{x}$ phosphorus product (CaxP), alkaline phosphatase, parathormone, hemoglobin and C-reactive protein (CRP) levels in both dialysis groups $(p>0.05)$.

In endoscopic examination; only 3 patients had an ulcerous lesion, while all patients had non-ulcerous lesions. There was no difference between gastroesophageal reflux disease (GERD), ulcerated lesion and nonulcerated lesion rates in both dialysis groups (Table 1). According to histopathological findings, the frequency of HP positivity was significantly higher in the PD group $(p=0.046)$. However, the frequency of other pathological findings was similar in both dialysis groups. No patient had dysplasia (Table 2).

The characteristics of dialysis patient with $(n=40)$ and without $(n=13)$ chronic gastritis were compared. The HP positivity rate in the group with chronic gastritis was $37.5 \%(n=15)$. HP was negative in the group without chronic gastritis $(p=0.011)$. In the group with chronic gastritis, median sodium [140(129:145) vs. 138(133:142) $\mathrm{mmol} / \mathrm{L}, p=0.033)$ and LDL cholesterol [146(77:217) vs. $118(54: 180) \mathrm{mg} / \mathrm{dL}, p=0.043)]$ and mean total protein $(6.76 \pm 0.58$ vs. $6.24 \pm 0.72 \mathrm{~g} / \mathrm{dL}, p=0.012)$ and albumin $(4.07 \pm 0.39$ vs $3.77 \pm 0.43 \mathrm{~g} / \mathrm{dL}, p=0.027)$ levels were higher. Mean urea $(98.4 \pm 23$ vs. $125.2 \pm 38.7 \mathrm{mg} / \mathrm{dL}, p=$ $0.032)$ and median ferritin [191.5(10.4:2000) vs. 358(62.4: 1799) $\mathrm{mcg} / \mathrm{L}, p=0.043)$ ] levels were lower in the group with chronic gastritis.

HP infection was detected in $28.3 \%$ of dialysis patients. The characteristics of dialysis patient with $(n=15)$ and without $(n=38)$ HP were compared. In endoscopic examination, gastritis rate in the HP positive group (86.7\% vs. $52.6 \%, p=0.021)$ was higher than negative group and erosive gastritis rate $(44.7 \%$ vs. $13.3 \%, p=$
0.032) was higher in HP negative group than positive group. In histopathological examination, while chronic gastritis was observed in all HP positive group (100\%), the rate of chronic gastritis in the HP negative group was $65.8 \%(n=25, p=0.011)$. There was no intestinal metaplasia in the HP positive group. This rate was $23.7 \%$ $(n=9)$ in the HP negative group $(p=0.047)$. The mean total cholesterol level in the HP positive group was higher than the HP negative group $(229.6 \pm 39.9$ vs. $202.6 \pm 37.1 \mathrm{mg} / \mathrm{dL}, p=0.023)$. Median dialysis durations of HP positive [22.0(1.25:171.2) month] and negative [30.3(1.31:171.2) month] groups were comparable $(p=0.984)$.

\section{Risk analysis}

The independent risk factors affecting the development of endoscopic gastritis and duedonitis and pathological chronic gastritis and HP were determined with multivariable logistic regression analysis. The logistic regression models obtained in the final step of the analysis were found significant and the data set was compatible with the models. Regression analysis models for each dependent variable included the following variables: pathological chronic gastritis, HP positivity, hypertension, triglyceride, LDL cholesterol and CRP for the presence of endoscopic gastritis (Model $\chi^{2}=9.17 ; p=0.010$, $\mathrm{R} 2=21.6 \%$, Hosmer and Lemeshow Test: $p=0.183)$; age, dialysis duration, GERD, Kt/V, sodium, chloride, total cholesterol, hemoglobin, calcium, phosphorus, CaxP and lipase for the presence of endoscopic duedonitis (Model $\chi^{2}=30.55 ; p<0.001, \mathrm{R} 2=58.4 \%$, Hosmer and Lemeshow Test: $p=0.492$ ); gender, endoscopic ulcerous lesion and gastritis, Kt/V, urea, sodium, chloride, total protein, albumin, LDL cholesterol, TSAT, ferritin, phosphorus and CaxP for the presence of pathological chronic gastritis (Model $\chi^{2}=18.45 ; p<0.001, \mathrm{R} 2=43.8 \%$, Hosmer and

Table 1 Comparison of endoscopic findings in groups

\begin{tabular}{|c|c|c|c|c|}
\hline Variables, n(\%) & Total $(n=53)$ & $\mathrm{PD}(n=31)$ & $\mathrm{HD}(n=22)$ & $p$-value \\
\hline Gastroesophageal reflux disease & $22(41.5 \%)$ & $14(45.2 \%)$ & $8(36.4 \%)$ & $0.522^{a}$ \\
\hline \multicolumn{5}{|l|}{ Non-ulcerous lesion } \\
\hline Gastritis & $33(62.3 \%)$ & $19(61.3 \%)$ & $14(63.6 \%)$ & $0.862^{\mathrm{a}}$ \\
\hline Erosive gastritis & $19(35.8 \%)$ & $12(38.7 \%)$ & $7(31.8 \%)$ & $0.606^{\mathrm{a}}$ \\
\hline Esophagitis & $7(13.2 \%)$ & $6(19.4 \%)$ & $1(4.5 \%)$ & $0.218^{\mathrm{b}}$ \\
\hline Duodenal erosion/duodenitis & $10(18.9 \%)$ & $6(19.4 \%)$ & $4(18.2 \%)$ & $>0.99^{b}$ \\
\hline Polyp & $2(3.8 \%)$ & $1(3.2 \%)$ & $1(4.5 \%)$ & $>0.99^{b}$ \\
\hline Esophageal varicosis & $1(1.9 \%)$ & 0 & $1(4.5 \%)$ & $0.415^{\mathrm{b}}$ \\
\hline Ulcerous lesion & $3(5.7 \%)$ & $2(6.5 \%)$ & $1(4.5 \%)$ & $>0.99^{b}$ \\
\hline Gastric ulcer & $1(1.9 \%)$ & $1(3.2 \%)$ & 0 & $>0.99^{\mathrm{b}}$ \\
\hline Duodenal ulcer & $2(3.8 \%)$ & $1(3.2 \%)$ & $1(4.5 \%)$ & $>0.99^{b}$ \\
\hline Pyloric diverticulum & $1(1.9 \%)$ & 0 & $1(4.5 \%)$ & $0.415^{\mathrm{b}}$ \\
\hline
\end{tabular}

${ }^{\mathrm{a}}$ : Chi-square test, ${ }^{\mathrm{b}}$ : Fisher's exact test 
Table 2 Comparison of pathological findings in groups

\begin{tabular}{lllll}
\hline Variables, $\mathbf{n}(\%)$ & Total $(\boldsymbol{n}=\mathbf{5 3})$ & PD $(\boldsymbol{n}=\mathbf{3 1})$ & HD $(\boldsymbol{n}=\mathbf{2 2})$ & $\mathbf{p}$-value \\
\hline Chronic gastritis & $40(75.5 \%)$ & $24(77.4 \%)$ & $16(72.7 \%)$ & $0.696^{\mathrm{a}}$ \\
Non-spesific gastritis & $13(24.5 \%)$ & $7(22.6 \%)$ & $6(27.3 \%)$ & $0.696^{\mathrm{a}}$ \\
Intestinal metaplasia & $9(17 \%)$ & $5(16.1 \%)$ & $4(18.2 \%)$ & $>0.99^{\mathrm{b}}$ \\
Atrophy & $8(15.1 \%)$ & $3(9.7 \%)$ & $5(22.7 \%)$ & $3(13.6 \%)$ \\
Helicobacter pylori & $15(28.3 \%)$ & $12(38.7 \%)$ & $1(4.5 \%)$ & $0.253^{\mathrm{b}}$ \\
Serrated adenoma & $1(1.9 \%)$ & 0 & $1(4.5 \%)$ & $0.0415^{\mathrm{b}}$ \\
Hyperplastic polyp & $2(3.8 \%)$ & $1(3.2 \%)$ & 0 & $>0.99^{\mathrm{b}}$ \\
Dysplasia & 0 & 0 & & - \\
\hline
\end{tabular}

${ }^{a}$ :Chi-square test, ${ }^{b}$ : Fisher's exact test

Lemeshow Test: $p=0.623$ ) and gastritis, dialysis type, erosive gastritis, urea, $\mathrm{HbA1c}$, total cholesterol, LDL cholesterol, ferritin, calcium and gamma glutamyltransferase (GGT) for the presence of HP positivity (Model $\mathrm{X} 2=26.44 ; \mathrm{p}<0.001, \mathrm{R} 2=56.4 \%$, Hosmer and Lemeshow Test: $p=0.872$ ). In the multivariate analysis, only HP positivity $(p=0.040)$ influenced the presence of endoscopic gastritis. Hemoglobin $(p=0.027)$ and chloride levels $(p=0.013)$ influenced the presence of endoscopic duedonitis. Men gender $(p=0.030)$, urea $(p=0.014)$ and albumin levels $(p=0.048)$ influenced the presence of pathological chronic gastritis. The presence of gastritis $(p=0.040)$, total cholesterol $(p=0.006)$ and ferritin levels $(p=0.048)$ influenced HP positivity. Variables in the models formed in the final step of multivariable logistic regression analysis were showed in Table 3.

In ROC curve analysis, the cut-off point for hemoglobin was determined as $>10.7 \mathrm{~g} / \mathrm{dL}$ for the sensitivity and specificity of hemoglobin for predicting the presence of duodenitis. The area under the curve for hemoglobin was 0.68 (sensitivity $100 \%$, specificity $39.53 \%, p=0.022$ ). The cut-off point for urea was determined as $\leq 112 \mathrm{mg} / \mathrm{dL}$ for the sensitivity and specificity of urea for predicting the presence of chronic gastritis. The area under the curve for urea was 0.72 (sensitivity $80 \%$, specificity $61.54 \%, p=0.017$ ). The cut-off point for total cholesterol was determined as $>243 \mathrm{mg} / \mathrm{dL}$ for the sensitivity and specificity of total cholesterol for predicting the presence of HP positivity (Fig. 1). The area under the curve for total cholesterol was 0.69 (sensitivity $46.67 \%$, specificity $86.84 \%, p=0.026$ ).

\section{Discussion}

The incidence of gastrointestinal disorders is high in patients with CKD due to increased risk of gastric mucosal damage associated with high ammonia levels, systemic and/or local chronic circulatory failure and hypergastrinemia [17]. In 5161 dialysis patients (3804 HD and 1507 $\mathrm{PD})$, the most prevalent symptoms were constipation, indigestion, abdominal pain and reflux [18]. However, there is no good correlation between the symptoms of the patients and endoscopic gastroduodenal lesions [19, $20]$. In one study, $73.8 \%$ of the patients were asymptomatic, whereas $35.9 \%$ of the patients had normal endoscopy [20]. In contrast, some studies report lower rates of normal mucosal findings on endoscopy in HD patients, ranging from 9.3 to $17.5 \%$ [21, 22]. Asymptomatic gastroduodenal lesions such as erosive gastroduodenitis and peptic ulcer may be seen in $46 \%$ of end-stage renal disease (ESRD) patients [23]. There may be a positive correlation between upper gastrointestinal lesions and CKD severity. Upper gastrointestinal lesions are seen in $80 \%$ of patients with advanced CKD and dialysis [24].

Table 3 Multivariable logistic regression analysis of independent risk factors affecting the development of endoscopic gastritis and duedonitis and pathological chronic gastritis and HP positivity

$\begin{array}{lllll}\text { Wald } & \begin{array}{l}p- \\ \text { value }\end{array} & \begin{array}{l}\text { Odds } \\ \text { ratio } \\ \text { (OR) }\end{array} & \text { Lower } & \text { Upper }\end{array}$

\begin{tabular}{llllll}
\hline Gastritis & & & & & \\
HP (presence) & 4.22 & $\mathbf{0 . 0 4 0}$ & 5.71 & 1.08 & 30.05 \\
CRP & 2.17 & 0.140 & 0.87 & 0.72 & 1.05 \\
Duodenitis & & & & & \\
GERD (presence) & 2.84 & 0.092 & 4.02 & 0.80 & 20.30 \\
Chloride & 6.22 & $\mathbf{0 . 0 1 3}$ & 0.90 & 0.83 & 0.98 \\
Hemoglobin & 4.87 & $\mathbf{0 . 0 2 7}$ & 2.21 & 1.09 & 4.45 \\
Chronic gastritis & & & & & \\
Gender (male) & 4.69 & $\mathbf{0 . 0 3 0}$ & 9.90 & 1.24 & 78.83 \\
Urea & 6.01 & $\mathbf{0 . 0 1 4}$ & 0.95 & 0.91 & 0.99 \\
Albumin & 3.90 & $\mathbf{0 . 0 4 8}$ & 8.83 & 1.02 & 76.79 \\
HP positivity & & & & & \\
Gastritis (presence) & 4.20 & $\mathbf{0 . 0 4 0}$ & 9.50 & 1.10 & 81.90 \\
Total cholesterol & 7.59 & $\mathbf{0 . 0 0 6}$ & 1.04 & 1.01 & 1.06 \\
GGT & 3.08 & 0.079 & 0.91 & 0.83 & 1.01 \\
Ferritin & 3.93 & $\mathbf{0 . 0 4 8}$ & 0.97 & 0.97 & 0.99 \\
\hline
\end{tabular}

HP Helicobacter pylori, Cl confidence interval, CRP C-reactive protein, GERD gastroesophageal reflux disease, GGT gamma glutamyltransferase (GGT) 


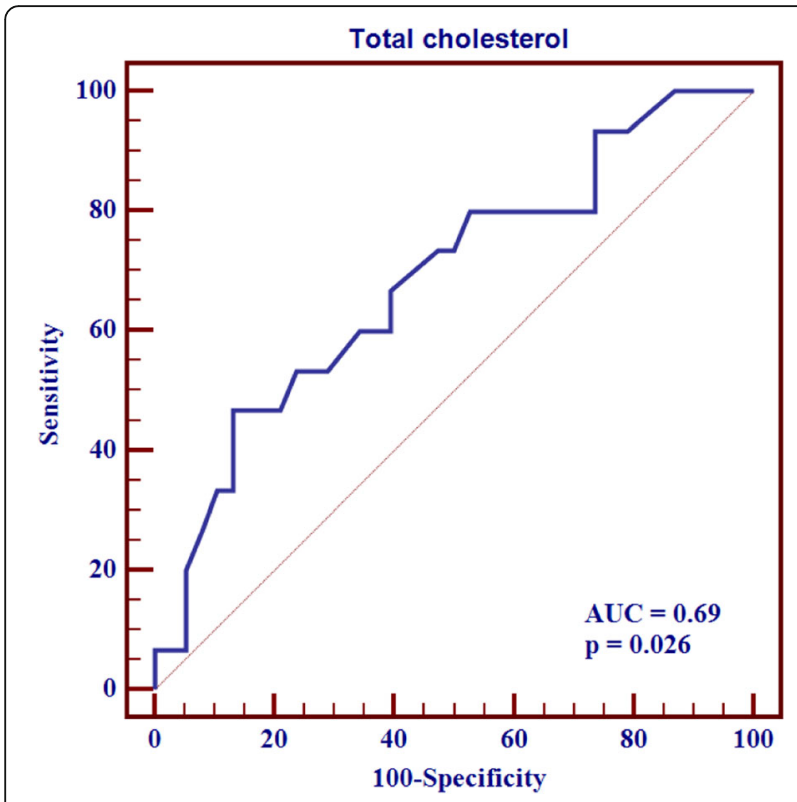

Fig. 1 The realtioship between total cholesterol and Helicobacter pylori positivity

Despite similarities, the definition and frequency of esophagagastroduodenal lesions in endocopic examination varies in most studies. Abnormal endoscopic findings of patients on maintenance HD were erosive esophagitis (30.2\%), gastroesophageal reflux disease (GERD, 10\%), esophagitis (5.8\%), enanthematous pangastritis (57.3\%), diffuse antral erythema (27.8\%), gastric erosion (58\%), gastric antral erosion (22.8\%), gastric intestinal metaplasia (8.33\%), gastritis and duodenitis (42\%), duodenal erosion (18-32\%), nodular duodenum (2\%), peptic ulcer (7.3\%), gastric ulcer (7-14\%), duodenal ulcer (7.3-18.4\%), angiodysplasia (4.4\%) and inflammatory gastric polyps (1.5\%) in different studies [19, 20, 25-27]. In a large dialysis cohort, endoscopic examination revealed $77.8 \%$ gastritis, $11.4 \%$ gastric ulcer, $6.4 \%$ duodenal ulcer and $1.7 \%$ gastric cancer. On the other hand, $92.6 \%$ gastritis, $4.1 \%$ gastric ulcer and $3.3 \%$ duodenal ulcer were detected in the annual health checks of patients with normal renal function [9]. In endoscopic examination, hiatus hernia ( $29.3 \%$ vs. $14 \%)$ was more frequent and duodenal ulcer $(3.26 \%$ vs. $16 \%)$ was lower in dialysis patients compared with non-uremic dyspeptic patients [28]. In our cohort, the most common non-ulcerous lesions in the endoscopic examination of dialysis patients with dyspeptic symptoms were gastritis (62.3\%), erosive gastritis (38.7\%), duodenal erosion/duodenitis (18.9\%) and esophagitis (13.2\%). When the frequency of gastrointestinal disorders was compared in 8955 non-uremic patients, $1791 \mathrm{PD}$ and 8955 HD patients, GERD, abdominal hernia, intestinal obstruction or adhesions in PD group and peptic ulcer disease, lower gastrointestinal diverticulum and hemorrhage in HD group was significantly higher than in other groups
[29]. Among 422 patients with ESRD on maintenance dialysis 322 were endoscopied, and patients who had erosive pre-pyloric changes of grade 2 and 3 were older, receiving dialysis longer, and more likely to be on HD rather than PD when compared with patients without erosive prepyloric changes [30]. More exposure to inflammatory conditions and oxidative stress in HD can damage or aggravate the stomach or small intestine mucosa. The other potential reasons of peptic ulcer in HD patients may be anticoagulant use, intradialytic hypotension and hemodynamic changes [31]. Ulcerous lesions were found in our 3 patients (5.7\%). One patient with hepatitis B had only esophageal varicosis. However, the difference between the frequency of endoscopic lesions in PD and HD patients was not significant.

GERD is a common upper gastrointestinal disorder in patients with CKD (77.5\%) and kidney transplant (75\%) patients than normal population $(38.6 \%)$ with the same upper gastrointestinal symptoms, while HP infection was lower (40, 36.1 and 75\%, respectively). Although there was no significant difference between the prevalences of GERD (33.3 and 39.5\%), erosive reflux esophagitis (16.7 and 23.7\%) and non-erosive reflux disease (16.7 and 13.2\%) in $\mathrm{PD}$ and HD, respectively, their prevalences were higher than those of the general population [32-34]. CKD, PD, gastrointestinal amyloidosis, immunosuppression and absence of HP infection seem to be risk factors for the development of GERD in ESRD patients [32, 35]. Some studies found to be similar the prevalences of GERD in ESRD patients and non-CKD controls with the same upper gastrointestinal symptoms $[34,35]$. The frequency of GERD in our patients was $41.5 \%$. GERD rate was higher in PD patients than in HD patients ( $45.2 \%$ vs. $36.4 \%)$, but this difference did not reach statistical significance. PD patients had more severe reflux and eating dysfunction than HD and pre-dialytic patients $[1,36]$. Higher prevalence of GERD has been shown in PD patients than in HD patients ( $44.6 \%$ vs. $19.8 \%$ ). This may be due to increased intraperitoneal pressure by PD [37].

In various studies, erosive gastritis, atrophic gastritis, and intestinal metaplasia was found in normal population 42.3, 17.7, and 23.6\%, respectively. Endoscopic and pathological findings are generally reported to be consistent in patients with ESRD. The most common abnormality in HD patients was chronic gastritis with a rate of $30 \%$ in esophagogastroduodenoscopy and $71.5 \%$ in upper gastrointestinal mucosa [21, 38]. Endoscopy was performed in $322(76.3 \%)$ of 422 dialysis patients and gastroduodenal biopsy samples were taken from 260 patients (80.7\%). Gastroduodenitis was $49 \%$ in endoscopy, gastritis was $52 \%$ and duodenitis was $21 \%$ on histological examination [39]. In a study where endoscopic findings were chronic gastritis (37\%), acute gastritis (20.1\%), duodenal ulcer (11.1\%), erosive or non-erosive duodenitis (9.3\%), gastroduodenitis 
(5.56\%) and GERD (3.7\%), histological examination of multiple antral gastric biopsies revealed chronic active gastritis in $51.9 \%$ of patients [22]. In another study, gastric mucosal oedema (82.3\%), gastritis (23.5\%) and increase in number of bi- and multinucleated parietal cells with vacuolation and fragmentation of the cytoplasm (29\%), Brunner's gland hyperplasia (82.4\%), duodenitis (70.6\%) and gastric metaplasia in duodenum (29.4\%) were the main histological changes [40]. The most common pathological finding in our dialysis patients was chronic gastritis (75.5\%). The frequencies of intestinal metaplasia and atrophy were 17 and $15.1 \%$, respectively. We did not find dysplasia and neoplasia. Atrophy rate was higher in HD patients than in PD patients, but this difference did not reach statistical significance $(22.7 \%$ vs. $9.7 \%)$. The HP positivity rate in patients with chronic gastritis was $37.5 \%$, while HP was negative in patients without chronic gastritis. In our patients with chronic gastritis, sodium and LDL cholesterol, total protein and albumin levels were higher and urea and ferritin levels were lower.

In our study, the probability of developing chronic gastritis in men was 9.9-fold higher than in women. The presence of gastritis increased the risk of HP positivity by 9.5fold. Male gender and HP infection are associated with a higher risk of the important endoscopic lesions including esophagitis, gastroduodenal erosions and peptic ulcers, but not age, duration of dialysis, cause of the ESRD, presence of any symptoms, and hemoglobin levels [20]. Interestingly, we found in our study that one unit increase in hemoglobin level increased the risk of duodenitis by 2.21fold. A hemoglobin $>10.7 \mathrm{~g} / \mathrm{dL}$ was significantly related to an increased risk of the presence of duodenitis. One unit increase in chloride level reduced the risk of duodenitis by $10 \%$. One-unit increase in ferritin level reduced the risk of $\mathrm{HP}$ positivity by $3 \%$. Indeed, HP has been identified as a possible cause of vitamin B12 and iron deficiency in the general population. HP may have an independent role in anemia of HD patients due to gastroduodenal blood loss [41]. HP-positive HD patients may present with lower vitamin B12 blood levels [42].

Gastric and duedonal ulcers were seen in the normal population between 11 and 20\% [43]. A study found that $\mathrm{HP}$ infection was an independent protective factor for gastric erosion, but it was not associated with other mucosal lesions [26]. In a retrospective study of 827 dialysis patients during the 10-year study period, peptic ulcers were detected in 153 of 481 patients underwent endoscopy. Age, PD, diabetes mellitus, congestive heart failure, low serum albumin and high GGT levels are risk factors for peptic ulcers among ESRD patients [44]. Dialysis patients with peptic ulcer had lower serum albumin levels and higher blood urea nitrogen (BUN) levels than non-ulcer patients. Malnourished patients often show a gradual decrease in BUN levels [31]. Inflammatory stress and malnutrition can impair the gastric mucosa function and induce peptic ulcers. Hypoalbuminemia is one of the strongest predictors for morbidity and mortality in patients with ESRD. Serum albumin concentration correlates not only with lower protein intake, but also with inflammation. Patients with worse gastrointestinal symptoms had lower dietary protein intake. Gastrointestinal symptoms and inflammation were risk factors for lower serum albumin levels [45]. Gastrointestinal symptoms cause reduced food intake in 53\% of PD patients and 14\% of HD patients. Dietary changes can alleviate symptoms in 34\% of PD patients and 9\% of HD patients [46]. However, the increased albumin level in our patients increased the risk of chronic gastritis by 8.83 -fold. In fact, a good diet that leads to an increase in albumin and urea levels may increase gastric complaints and lesions.

The incidence of HP varies between 24 and 32\% in general population [47]. HP positivity was found in $28.3 \%$ of our patients. HP positivity rate in PD patients was significantly higher than in HD patients $(38.7 \%$ vs. $13.6 \%)$. The rate of HP infection in uremic patients varies between 24 and $73 \%$ in different studies $[3,9,19,22,25,26,46,48]$. The prevalence of HP positivity in ESRD patients was significantly lower than those of non-CKD patients (27.5$38.1 \%$ vs. $56-67.4 \%)[26,34]$, but it was not confirmed in all studies [2, 25, 48]. Different studies have reported a relationship between the presence of HP with chronic active gastritis, non-erosive esophagitis and gastric metaplasia [19, $22,41,49,50]$. Among peptic ulcer disease, HP infection rate in the CKD (58.5\%) and ESRD (56.2\%) patients was lower than in non-CKD patients (70.3\%) [3]. Upper gastrointestinal endoscopic examination has shown the presence of severe HP pangastritis even in some patients without significant complaints [4]. In recent study, $78.6 \%$ of patients had non-HP-related gastritis, $38.9 \%$ had duodenitis and $32.2 \%$ had HP infection. Duodenitis was associated with tacrolimus use [51]. Interestingly, a lower HP gastritis rate of 9.2 to $29 \%$ has been reported in gastric biopsies of kidney transplant patients $[16,48,52]$. However, in a small cohort, kidney transplant recipients have had a higher prevalence of HP infection than dialysis and control dyspeptic patients (62\% vs. 34.6 and $43.6 \%$, respectively). The rate of active gastritis in transplant $(6.9 \%)$ and dialysis (3.8\%) groups was lower than in control subjects (31.3\%) [53]. In the present cohort, the rate of gastritis in HP-positive patients $(86.7 \%$ vs. 52.6\%) and erosive gastritis rate in HP-negative patients (44.7\% vs $13.3 \%)$ were higher than the other. There was also a significant difference between chronic gastritis $(65.8 \%$ vs. $100 \%$ ) and intestinal metaplasia (0\% vs. $23.7 \%$ ) in HPpositive and negative patients, respectively.

The mean duration of dialysis in HP-positive patients is significantly lower than in HP-negative patients. In our study, median dialysis duration in HP-positive patients was shorter than HP-negative patients, but this difference 
was not statistically significant ( 22 vs. 30.3 months). The low number of patients in both groups may be the reason for not reaching statistical significance. Chronic gastritisrelated gastric acid hyposecretion may decrease the prevalence of HP in long-term dialysis patients [10]. Other studies have also shown that the prevalence of HP infection decreases significantly as the duration of dialysis prolongs, especially within the first 4 years after the start of dialysis $[8,9,27]$. A meta-analysis of dialysis patients found that the HP infection rate was negatively correlated with the duration of dialysis [54]. Recently, two separate meta-analyzes reported a lower estimated prevalence of HP infection, such as $44 \%$ in ESRD patients and $48.2 \%$ in CKD patients compared to non-CKD patients $[17,55]$. Indeed, there is a direct relationship between the duration of dialysis and the incidence of gastric metaplasia [56]. The presence of HP was associated with the occurrence of histological gastritis in both body and antral mucosa, strongly correlated with acute gastritis and acute on chronic gastritis rather than chronic gastritis [39]. If HP positivity was observed in our study, the risk of gastritis increased 5.71-fold. The decrease in HP infection rate with longer dialysis duration can be explained by several mechanisms. In HD patients, high blood urea levels can contribute to a decreased gastric acid secretion and higher gastric $\mathrm{pH}$, and may inhibit the growth of $\mathrm{HP}$ in the gastrointestinal tract. In our study, one-unit increase in serum urea level was shown to reduce the risk of chronic gastritis by $5 \%$, but a single BUN measurement can be misleading. However, an urea $\leq 112 \mathrm{mg} / \mathrm{dL}$ was significantly related to an increased risk of the presence of chronic gastritis.

The usages of antibiotics, proton pump inhibitors or $\mathrm{H}_{2}$ receptor antagonists in dialysis patients may inhibit HP growth. Severe gastric mucosal atrophy leading to decreased $\mathrm{H}^{+}$secretion may occur in HD patients secreting inflammatory cytokines. In addition, secretion of inflammatory cytokines in HD patients cause severe chronic gastritis leading to decreased secretion of $\mathrm{H}^{+}$, and this affect the colonization of HP in the gastric mucosa $[54,57]$. In contrast, some studies have shown that high urea concentrations make the gastric mucosa more susceptible to HP, and uremic patients have a higher infection rate. The high incidence of peptic ulcers in CKD patients is caused by various reasons other than HP infection [58]. Among ESRD patients without symptom, serum pepsinogen I/II ratio was significantly higher in HP-negative patients than in HP-positive patients [26].

In our study, total cholesterol level in HP-positive patients was higher than HP-negative patients. Hypocholesterolemia $(<140 \mathrm{mg} / \mathrm{dL})$ was associated with higher mortality in hemodialysis patients [31]. One-unit increase in total cholesterol level increased risk of HP positivity by 1.04 -fold. A total cholesterol $>243 \mathrm{mg} / \mathrm{dL}$ was significantly related to an increased risk of the presence of HP positivity. Statins reduce cellular cholesterol and risk of HP infection by decreasing HP burden in macrophages, and consequently alleviate inflammation caused by HP [58]. Also, depletion of cholesterol has been demonstrated to attenuate CagA-induced pathogenesis [59]. Adding statin to the standard triple therapy may improve the eradication rate of $\mathrm{HP}$ infection [60].

Many studies did not find a significant relationship between anemia and iron deficiency with HP positivity and other endoscopic findings except bleeding [61]. We detected significant relationship between duedonitis and lower hemoglobin. We evaluated anemia as the primary outcome of CKD, independent of HP positivity.

Chronic gastritis described in approximately $50 \%$ of uremic patients [62]. We found it significantly too. Inflammation and medications may affected this condition. Hypoalbuminemia detected in $81 \%$ of patients with gastropathy [63]. Hypoalbuminemia becomes evident when kidney failure progresses, depending on nutrition and inflammatry process [45]. In our study, We found albumin levels low, as in the literature.

\section{Conclusions}

Gastrointestinal non-ulcerous lesions are common in dyspeptic dialysis patients. Dialysis modality may affect the frequency of some lesions. Although our study included relatively low number of patients in a single center, HP positivity was more common in PD patients than in HD patients. Chronic gastritis was observed in most patients $(75.5 \%)$ and $37.5 \%$ of them were HP-positive. In our study, we only highlighted patological data and findings. Gender was only significantly in patients with chronic gastritis. The results of our study also show that it is beneficial in HP eradication to control serum total cholesterol levels in patients with HP positivity. Even if they have dyspeptic symptoms, it may be useful to evaluate dialysis patients by endoscopic examination and to treat those with gastrointestinal lesions.

The number of patients was one of our most important limitations. We do not apply upper gastrointestinal system endoscopy routinely in our institution, except patients who have active complaints and symptoms.

\footnotetext{
Abbreviations

PD: Peritoneal dialysis; HD: Hemodialysis; HP: Helicobacter pylori; CKD: Chronic kidney disease; MALT: Mucosa Associated Lymphoid Tissue; ROC: Receiver operator characteristic; HIV: Human immunodeficiency virus; HCV: Hepatitis C; SD: Standart deviation; Min: Minimum; Max: Maximum; CRP: C reactive protein; LDL: Low dansity lipoprotein; TSAT: Transferrin saturation; HbA1C: Hemoglobin A1C; GGT: Gamma glutamyltransferase; ESRD: End stage renal disease; GERD: Gastroesophageal reflux disease; BUN: Blood urea nitrogen
}

Acknowledgements Not Applicable. 


\section{Authors' contributions}

Data collecting: MU, AE, YA.Statistical analysis: GO.Endoscopy: BY, EDE.Pathological evaluation: OE.Writing, interpretation of data: AE, YA. The author(s) read and approved the final manuscript.

\section{Funding}

No funding was obtained for this study.

\section{Availability of data and materials}

All or part of the data in this study did not publish and present in another journal or meeting. The datasets used and/or analysed during the current study are available from the corresponding author on reasonable request.

\section{Ethics approval and consent to participate}

Ethics committee approval was taken from Kütahya Sciences of Health University on 01/08/2019 with number 189 . All participants provided written informed consent.

\section{Consent for publication}

Not Applicable.

\section{Competing interests}

There is no conflict of interest among the authors.

\section{Author details}

'Bursa City Hospital, Department of Nephrology, Nephrology Clinic, Dogankoy mevki, Nilufer, Bursa, Turkey. ${ }^{2}$ Division of Nephrology, Department of Internal Medicine, Bursa Uludag University Faculty of Medicine, Gorukle, Nilufer, Bursa, Turkey. ${ }^{3}$ Faculty of Medicine, Department of Bioistatistics, Uludag University, Gorukle, Nilufer, Bursa, Turkey. ${ }^{4}$ Bursa State Hospital, Department of Gastroenterology, Gastroenterology Clinic, Osmangazi, Bursa, Turkey. ${ }^{5}$ Department of Pathology, Bursa City Hospital, Dogankoy mevki, Nilufer, Bursa, Turkey.

Received: 17 March 2020 Accepted: 14 October 2020

Published online: 22 October 2020

\section{References}

1. Strid H, Simrén M, Johansson AC, Svedlund J, Samuelsson O, Björnsson ES. The prevalence of gastrointestinal symptoms in patients with chronic renal failure is increased and associated with impaired psychological general wellbeing. Nephrol Dial Transplant. 2002;17(8):1434-9.

2. $\operatorname{Var}$ C, Gültekin F, Candan F, Türkay C, Sencan M, Içağasioğlu S, et al. The effects of hemodialysis on duodenal and gastric mucosal changes in uremic patients. Clin Nephrol. 1996;45(5):310-4.

3. Chang SS, Hu HY. Lower helicobacter pylori infection rate in chronic kidney disease and end-stage renal disease patients with peptic ulcer disease. J Chin Med Assoc. 2014;77(7):354-9. https://doi.org/10.1016/j.jcma.2014.04.004 Epub 2014 Jun 3

4. Chrysoula P, Fotios N, Kostantina T. Severe gastric lesions due to helicobacter pylori infection in two patients undergoing hemodialysis. Ren Fail. 2014;36(9):1471. https://doi.org/10.3109/0886022X.2014.943671 Epub 2014 Jul 29

5. Kotilea K, Bontems P, Touati E. Epidemiology, diagnosis and risk factors of helicobacter pylori infection. Adv Exp Med Biol. 2019;1149:17-33. https://doi.org/10.1007/5584_2019_357.

6. Leja M, Grinberga-Derica I, Bilgilier C, Steininger C. Review: Epidemiology of Helicobacter pylori infection. Helicobacter. 2019;24 Suppl 1:e12635. doi: https://doi.org/10.1111/hel.12635

7. Ishikura N, Usui Y, Ito H, Kasugai Y, Oze I, Kato S, et al. Helicobacter pylori (HP) infection alone, but not HP-induced atrophic gastritis, increases the risk of gastric lymphoma: a case-control study in Japan. Ann Hematol. 2019; 98(8):1981-7. https://doi.org/10.1007/s00277-019-03721-y Epub 2019 Jun 8.

8. Sugimoto M, Yamaoka Y. Review of helicobacter pylori infection and chronic renal failure. Ther Apher Dial. 2011;15(1):1-9. https://doi.org/10. 1111/j.1744-9987.2010.00851.x Epub 2010 Aug 31.

9. Sugimoto M, Sakai K, Kita M, Imanishi J, Yamaoka Y. Prevalence of helicobacter pylori infection in long-term hemodialysis patients. Kidney Int. 2009;75(1):96-103. https://doi.org/10.1038/ki.2008.508 Epub 2008 Oct 8.
10. Nakajima F, Sakaguchi M, Amemoto K, Oka H, Kubo M, Shibahara N, et al. Helicobacter pylori in patients receiving long-term dialysis. Am J Nephrol. 2002;22(5-6):468-72.

11. Zhou F, Zhong X, Chen J, Li C, Shang M, Jiang C, et al. Helicobacter pylor infection associated with type 2 diabetic nephropathy in patients with dyspeptic symptoms. Diabetes Res Clin Pract. 2015;110(3):328-34. https:// doi.org/10.1016/j.diabres.2015.09.008 Epub 2015 Sep 25.

12. Ozgür $\mathrm{O}$, Boyacioğlu $\mathrm{S}$, Ozdoğan $\mathrm{M}$, Gür $\mathrm{G}$, Telatar $\mathrm{H}$, Haberal M. Helicobacter pylori infection in haemodialysis patients and renal transplant recipients. Nephrol Dial Transplant. 1997;12(2):289-91.

13. Tonkic A, Tonkic M, Lehours P, Mégraud F. Epidemiology and diagnosis of helicobacter pylori infection. Helicobacter. 2012;17(Suppl 1):1-8.

14. Chang WC, Jo YI, Park HS, Jegal J, Park JH, Lee JH, Jin CJ. Helicobacter pylori eradication with a 7-day low-dose triple therapy in hemodialysis patients. Clin Exp Nephrol. 2010;14(5):469-73. https://doi.org/10.1007/s10157-0100319-7 Epub 2010 Jul 15

15. Khedmat $H$, Ahmadzad-Asl M, Amini M, Lessan-Pezeshki M, Einollahi B, Pourfarziani V, et al. Gastro-duodenal lesions and helicobacter pylor infection in uremic patients and renal transplant recipients. Transplant Proc. 2007;39(4):1003-7

16. Ishaque M, Rashid R, Mubarak M. Gastrointestinal complications in renal transplant recipients detected by endoscopic biopsies in a developing country. Indian J Gastroenterol. 2015;34(1):51-7. https://doi.org/10.1007/ s12664-015-0537-8 Epub 2015 Mar 12.

17. Wijarnpreecha $K$, Thongprayoon C, Nissaisorakarn P, Lekuthai $N$, Jaruvongvanich V, Nakkala K, et al. Association between helicobacter pylori and end-stage renal disease: a meta-analysis. World J Gastroenterol. 2017; 23(8):1497-506. https://doi.org/10.3748/wjg.v23.i8.1497.

18. Zuvela J, Trimingham C, LeLeu R, Faull R, Clayton P, Jesudason S, Meade A. Gastrointestinal symptoms in patients receiving dialysis: a systematic review. Nephrology (Carlton). 2018;23(8):718-27. https://doi.org/10.1111/nep.13243.

19. Homse Netto JP, Pinheiro JPS, Ferrari ML, Soares MT, Silveira RAG, Maioli ME, Delfino VDA. Upper gastrointestinal alterations in kidney transplant candidates. [article in English, Portuguese]. J Bras Nefrol. 2018;40(3):266-72. https://doi.org/10.1590/2175-8239-JBN-3829 Epub 2018 May 14.

20. Sotoudehmanesh $R$, Asgari A, Ansari $R$, Nouraie M. Endoscopic findings in end-stage renal disease. Endoscopy. 2003;35(6):502-5.

21. Fabbian F, Catalano C, Bordin V, Balbi T, DiLandro D. Esophagogastroduodenoscopy in chronic hemodialysis patients: 2-year clinical experience in a renal unit. Clin Nephrol. 2002;58(1):54-9.

22. Al-Mueilo SH. Gastroduodenal lesions and helicobacter pylori infection in hemodialysis patients. Saudi Med J. 2004;25(8):1010-4.

23. Bunchorntavakul C, Atsawarungruangkit A. Prevalence of asymptomatic gastroduodenal lesions and helicobacter pylori infection in kidney transplant candidates. J Med Assoc Thail. 2014;97(Suppl 11):S62-8.

24. Ahmed W, Qureshi H, Zuberi SJ, Naqvi AJ, Mahmood S, Rafiq N. Endoscopic lesions in chronic renal failure. J Pak Med Assoc. 1993:43(5):95-6.

25. Karari EM, Lule GN, McLigeyo SO, Amayo EO. Endoscopic findings and the prevalence of helicobacter pylori in chronic renal failure patients with dyspepsia. East Afr Med J. 2000;77(8):406-9.

26. Moriyama T, Matsumoto T, Hirakawa K, Ikeda H, Tsuruya K, Hirakata H, lida M. Helicobacter pylori status and esophagogastroduodenal mucosal lesions in patients with end-stage renal failure on maintenance hemodialysis. J Gastroenterol. 2010;45(5):515-22. https://doi.org/10.1007/s00535-009-0196-6 Epub 2010 Jan 19.

27. Mortazavi F, Rafeey M. Endoscopic findings and helicobacter pylori in children on long-term hemodialysis. Pak J Biol Sci. 2008;11(14):1840-3.

28. AbuFarsakh NA, Roweily E, Rababaa M, Butchoun R. Brief report: evaluation of the upper gastrointestinal tract in uraemic patients undergoing haemodialysis. Nephrol Dial Transplant. 1996;11(5):847-50.

29. Lee YC, Hung SY, Wang HH, Wang HK, Lin CW, Chang MY, et al. Different risk of common gastrointestinal disease between groups undergoing hemodialysis or peritoneal Dialysis or with non-end stage renal disease: a Nationwide population-based cohort study. Medicine (Baltimore). 2015; 94(36):e1482. https://doi.org/10.1097/MD.0000000000001482.

30. Kang JY, Wee A, Choong HL, Wu AY. Erosive prepyloric changes in patients with end-stage renal failure undergoing maintenance dialysis treatment. Scand J Gastroenterol. 1990 Jul;25(7):746-50.

31. Kim M, Kim CS, Bae EH, Ma SK, Kim SW. Risk factors for peptic ulcer disease in patients with end-stage renal disease receiving dialysis. Kidney Res Clin Pract. 2019;38(1):81-89. doi: https://doi.org/10.23876/j.krcp.18.0060. 
32. Abdulrahman IS, Al-Quorain AA. Prevalence of gastroesophageal reflux disease and its association with helicobacter pylori infection in chronic renal failure patients and in renal transplant recipients. Saudi J Gastroenterol. 2008;14(4):183-6. https://doi.org/10.4103/1319-3767.41741.

33. Ness-Jensen $\mathrm{E}$, Hveem K, El-Serag H, Lagergren J. Lifestyle intervention in Gastroesophageal reflux disease. Clin Gastroenterol Hepatol. 2016;14(2):175-82.

34. Song HJ, Kim SM, Lee YM, Hwang JA, Moon KM, Moon CG, et al. Is there a difference in the prevalence of gastroesophageal reflux disease between peritoneal dialysis and hemodialysis patients? Korean J Gastroenterol. 2013;62(4):206-12.

35. Cekin AH, Boyacioglu S, Gursoy M, Bilezikci B, Gur G, Akin ED, et al. Gastroesophageal reflux disease in chronic renal failure patients with upper Gl symptoms: multivariate analysis of pathogenetic factors. Am J Gastroenterol. 2002;97(6):1352-6.

36. Dong R, Guo ZY, Ding JR, Zhou YY, Wu H. Gastrointestinal symptoms: a comparison between patients undergoing peritoneal dialysis and hemodialysis. World J Gastroenterol. 2014;20(32):11370-5. https:/doi.org/10.3748/wjg.v20.i32.11370.

37. Anderson JE, Yim KB, Crowell MD. Prevalence of gastroesophageal reflux disease in peritoneal dialysis and hemodialysis patients. Adv Perit Dial. 1999; 15:75-8.

38. Du Y, Bai Y, Xie P, Fang J, Wang X, Hou X, et al. Chinese chronic gastritis research group. Chronic gastritis in China: a national multi-center survey. BMC Gastroenterol. 2014;14:21.

39. Wee A, Kang JY, Ho MS, Choong HL, Wu AY, Sutherland IH. Gastroduodenal mucosa in uraemia: endoscopic and histological correlation and prevalence of helicobacter-like organisms. Gut. 1990;31(10):1093-6.

40. Misra V, Misra SP, Shukla SK, Jaiswal PK, Agarwal R, Tondon S. Endoscopic and histological changes in upper gastrointestinal tract of patients with chronic renal failure. Indian J Pathol Microbiol. 2004;47(2):170-3.

41. Khedmat H, Taheri S. Current knowledge on helicobacter pylori infection in end stage renal disease patients. Saudi J Kidney Dis Transpl. 2009;20(6):969-74.

42. Trimarchi $H$, Forrester M, Schropp J, Pereyra H, Freixas EA. Low initial vitamin B12 levels in helicobacter pylori--positive patients on chronic hemodialysis. Nephron Clin Pract. 2004;96(1):c28-32.

43. Pohl D, Keller PM, Bordier V, Wagner K. Review of current diagnostic methods and advances in helicobacter pylori diagnostics in the era of next generation sequencing. World J Gastroenterol. 2019;25(32):4629-60.

44. Chen YT, Yang WC, Lin CC, Ng YY, Chen JY, Li SY. Comparison of peptic ulcer disease risk between peritoneal and hemodialysis patients. Am J Nephrol. 2010;32(3):212-8. https://doi.org/10.1159/000316963 Epub 2010 Jul 16.

45. Zhang X, Bansal N, Go AS, Hsu CY. Gastrointestinal symptoms, inflammation and hypoalbuminemia in chronic kidney disease patients: a cross-sectional study. BMC Nephrol. 2015;16:211. https://doi.org/10.1186/s12882-015-0209-z.

46. Salamon K, Woods J, Paul E, Huggins C. Peritoneal dialysis patients have higher prevalence of gastrointestinal symptoms than hemodialysis patients. J Ren Nutr. 2013;23(2):114-8. https:/doi.org/10.1053/j.jn.2012.02.007 Epub 2012 May 26.

47. Shiotani A, Graham DY. Pathogenesis and therapy of gastric and duodenal ulcer disease. Med Clin North Am. 2002;86(6):1447-66.

48. Davenport A, Shallcross TM, Crabtree JE, Davison AM, Will EJ, Heatley RV Prevalence of helicobacter pylori in patients with end-stage renal failure and renal transplant recipients. Nephron. 1991;59(4):597-601.

49. Hooman N, Mehrazma M, Talachian E, Otukesh $H$, Nakhaii S. Helicobacter pylori infection in pediatric candidates for kidney transplantation. Iran J Kidney Dis. 2011;5(2):124-9.

50. Ala-Kaila K, Vaajalahti P, Karvonen AL, Kokki M. Gastric helicobacter and upper gastrointestinal symptoms in chronic renal failure. Ann Med. 1991:23(4):403-6.

51. Nazeer A, Rai AA, Luck NH. Factors leading to dyspepsia in renal transplant recipients. Pan Afr Med J. 2017;28:120. https://doi.org/10.11604/pamj.2017. 28.120.12767.

52. Wadhwa RK, Nazeer A, Rai AA, Luck NH. Role of endoscopic findings and biopsies in renal transplant recipients with gastrointestinal complications: a tertiary care experience. Exp Clin Transplant. 2018;16(5):522-7. https://doi. org/10.6002/ect.2017.0132 Epub 2018 Mar 9

53. Hruby Z, Myszka-Bijak K, Gościniak G, Błaszczuk J, Czyz W, Kowalski P, et al. Helicobacter pylori in kidney allograft recipients: high prevalence of colonization and low incidence of active inflammatory lesions. Nephron. 1997;75(1):25-9.

54. Li KJ, Chen L. Association between duration of dialysis and helicobacter pylor infection in dialysis patients: a meta-analysis. Int Urol Nephrol. 2019;51(8):1361-70. https://doi.org/10.1007/s11255-019-02205-2 Epub 2019 Jun 18.

55. Shin SP, Bang CS, Lee JJ, Baik GH. Helicobacter pylori infection in patients with chronic kidney disease: a systematic review and meta-analysis. Gut Liver. 2019;13(6):628-41. https://doi.org/10.5009/gnl18517.
56. Huang C, Chen Q, Jiang J, Zhang J, Bao B, Yao X. Gastric metaplasia and helicobacter pylori infection in hemodialysis patients. Ren Fail. 2012:34(4): 420-4. https://doi.org/10.3109/0886022X.2011.649659 Epub 2012 Jan 17.

57. Ahn JY. Prevalence of helicobacter pylori infection in patients with chronic kidney disease. Gut Liver. 2019;13(6):585-6. https://doi.org/10.5009/gnl19310.

58. Liao WC, Huang MZ, Wang ML, Lin CJ, Lu TL, Lo HR, et al. Statin decreases helicobacter pylori burden in macrophages by promoting autophagy. Front Cell Infect Microbiol. 2017;6:203. https://doi.org/10.3389/fcimb.2016.00203.

59. Lai CH, Chang YC, Du SY, Wang HJ, Kuo CH, Fang SH, et al. Cholesterol depletion reduces helicobacter pylori CagA translocation and CagA-induced responses in AGS cells. Infect Immun. 2008;76(7):3293-303. https://doi.org/ 10.1128/IAl.00365-08 Epub 2008 Apr 28.

60. Hassan AM, Shawky MAE, Mohammed AQ, Haridy MA, Eid KA. Simvastatin improves eradication rate of helicobacter pylori: upper Egypt experience. Infect Drug Resist. 2019:12:1529-34. https://doi.org/10.2147/IDR.S202346.

61. El-Said H, Attallah AHB, Ali-Eldin ZA. Does helicobacter pylori infection play a role in iron deficiency anemia in hemodialysis patients? Clin Nephrol. 2017:88(10):177-80

62. García Agudo R, Aoufi Rabih S, González Carro P, Pérez Roldán F, Proy Vega B, Arias Arias Á, et al. Gastrointestinal lesions in chronic kidney disease patients with anaemia. Nefrologia. 2019;39(1):50-7.

63. Meuwissen SG, Ridwan BU, Hasper HJ, Innemee G. Hypertrophic protein-losing gastropathy. A retrospective analysis of 40 cases in the Netherlands. The Dutch Ménétrier study group. Scand J Gastroenterol Suppl. 1992;194:1-7.

\section{Publisher's Note}

Springer Nature remains neutral with regard to jurisdictional claims in published maps and institutional affiliations.
Ready to submit your research? Choose BMC and benefit from:

- fast, convenient online submission

- thorough peer review by experienced researchers in your field

- rapid publication on acceptance

- support for research data, including large and complex data types

- gold Open Access which fosters wider collaboration and increased citations

- maximum visibility for your research: over $100 \mathrm{M}$ website views per year

At $\mathrm{BMC}$, research is always in progress.

Learn more biomedcentral.com/submissions 